\title{
PEREDA-BELTRÁN, N., GRECO A.M., BARTOLOMÉ M., SUÁREZ-SOTO E., KAN- TER B., FLOREANCING T.A., IZQUIERDO-MARTÍNEZ, G., ARCH M. \\ Guía Práctica para la Investigación Ética en Violencia contra la Infancia y la Adolescencia.
}

Universitat de Barcelona.

Eduardo Rodríguez Yunta ${ }^{1}$

La presente guía busca orientar, informar y señalar pautas de actuaciones éticas en investigación, con niños, niñas y adolescentes que han sufrido violencia en el contexto de países hispano-parlantes, siendo que no existen pautas específicas sobre el tema. Para la elaboración de la guía se ha recurrido a revisión bibliográfica y a orientaciones de investigadores relevantes de España y Latinoamérica que han trabajado en el área. Se exponen las respuestas que ofrecen los estudios publicados y se ilustra con casos reales las soluciones propuestas por los diferentes grupos de investigación.

Se abordan los siguientes temas: ¿por qué investigar en el área?; principios éticos básicos en investigación con niños, niñas y adolescente (autonomía, beneficencia y no maleficencia, justicia, espíritu de comunidad y solidaridad); aspectos que deben considerarse antes de iniciar la investigación (justificación, recursos humanos y económicos, necesidad de implicar a menores); consideraciones metodológicas (validez, perspectiva ética, recogida de datos y métodos de obtener información, disminución del riesgo de sesgo, disminución de la asimetría de poder entre investigador y participantes); consentimiento y asentimiento informado y voluntariedad (información que se debe proporcionar y como obtenerla, consentimiento de instituciones, qué hacer cuando el padre no consiente, tipos de consentimiento, consentimiento único del menor); daños y beneficios que se derivan de la participación de niños, niñas y adolescentes en estudios sobre violencia (minimización de daños, beneficios individuales, grupales y para la sociedad); privacidad y confidencialidad y cuándo debe romperse (como asegurar la privacidad, seguridad de la información, factores culturales, argumentos respecto a notificaciones obligatorias, procedimiento en caso de tener que romper la confidencialidad, ventajas y desventajas de identificarse en una investigación); cómo finalizar el estudio de forma adecuada (devolver y publicar los resultados, incidencia en la práctica profesional, beneficios potenciales y productos de la investigación).

Los autores constatan que se tiende a pensar que la investigación con menores es perjudicial, por la especial vulnerabilidad del grupo, pero esto atenta contra el principio de justicia y contradice la evidencia empírica: los niños, niñas y adolescentes son la fuente de información más precisa que existe cuando se investiga sobre ellos o sus experiencias, y tienen derecho a expresar su opinión.

La guía concluye con la responsabilidad ética en investigación con nińos, respetando su dignidad, con beneficios tanto individuales como grupales, de manera que incida en mejoras sociales, y teniendo en cuenta que el consentimiento informado debe hacerse de una forma continuada con los nińos.

\footnotetext{
${ }^{1}$ Centro Interdisciplinario de Estudios en Bioética, Universidad de Chile, Chile Correspondencia: erodriguezchi@gmail.com
} 